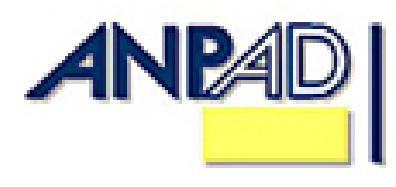

Available online at

http://www.anpad.org.br/bar

BAR, Rio de Janeiro, v. 10, n. 4, art. 2, pp. 389-414, Oct./Dec. 2013

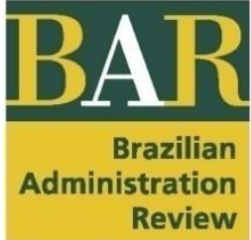

$(\mathrm{cos}) \mathrm{EY}-\mathrm{NC}$

\title{
Rhetorical Strategies of Consumer Activists: Reframing Market Offers to Promote Change
}

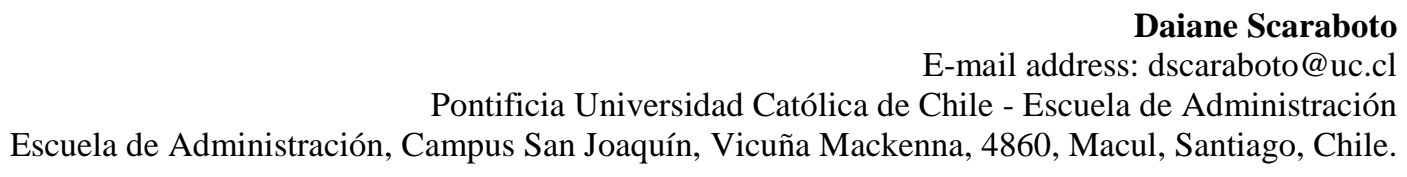

Severino Joaquim Nunes Pereira

E-mail address: bill.pereira4@gmail.com Universidade Federal Rural do Rio de Janeiro Av. Governador Roberto Silveira, Centro, 26285-060, Nova Iguaçu, RJ, Brazil.

Received 24 October 2012; received in revised form 5 April 2013 (this paper has been with the authors for two revisions); accepted 18 April 2013; published online $1^{\text {st }}$ October 2013. 


\begin{abstract}
Consumer researchers have most frequently looked at the influence the marketplace has on consumers' identity projects, while the reverse process - how consumers' identity projects influence the marketplace and general culture - is an important issue that has received less attention. Aiming to contribute to the development of this literature, we conduct a qualitative netnographic investigation of the Fat Acceptance Movement, an online-based movement led by consumer-activists who attempt to change societal attitudes about people who are fat. Our main goal is, therefore, to investigate how consumer activists who congregate online, that is, cyberactivists, reframe market offers while attempting to promote market and cultural change. We identify several rhetorical strategies employed by online consumer activists in their quests to change themselves, other consumers, and the broader culture. Our findings advance consumer research on how consumers may mobilize resources to initiate and promote self-, market-, and cultural transformations.
\end{abstract}

Key words: online activism; consumer identity; change; netnography; rhetorical strategies. 


\section{Introduction}

With the revitalization of blogs as networking platforms and the popularization of social media, consumer activists have found on the internet a platform to extend their capabilities of promoting social and cultural change - both online and offline. Consumer activism and similar contemporary movements tend to surge not only from political opportunities and organizational structures but also from the shared meanings and cultural resources available to individuals (Pichardo, 1997). New Social Movements theorists explain this form of activism as capable of assuming the shape of the broader cultural context, as well as of developing its own movement culture, one that might eventually be incorporated into the broader cultural context (Goodwin \& Jasper, 2009; Pichardo, 1997), although not without effort. Activists usually frame distinct movement cultures as alternatives to the status quo that the movement criticizes or challenges. These acts of framing have been considered a key factor in a movement's ability to successfully promote market and cultural change (Benford \& Snow, 2000).

Observing the cultural embeddedness of all forms of consumption, consumer researchers working in the Consumer Culture Theory tradition (CCT) have studied specific groups such as subcultures (e.g. Kates, 2002; Pereira \& Ayrosa, 2012; Schouten \& McAlexander, 1995) and online communities (e.g. Kozinets, 2002; Kozinets \& Handelman, 2004; Muñiz \& Schau, 2005) and their relationship to the market. This collective body of work has explored "the heterogeneous distribution of meanings and the multiplicity of overlapping cultural groupings that exist within the broader sociohistoric frame of globalization and market capitalism" (Arnould \& Thompson, 2005, p. 869). More specifically, CCT researchers have investigated consumer groups that oppose certain market practices or the entire market system, under the labels of consumer resistance (e.g. Fournier, 1998; Penaloza \& Price, 1993; Sandlin \& Callahan, 2009) or consumer activism (e.g. Hollenbeck \& Zinkham, 2006; Kozinets \& Handelman, 2004). Although highly relevant to our study, these bodies of work have not sufficiently addressed three important aspects of consumers' collective activism.

First, one of the key theoretical issues addressed by CCT researchers is how consumers draw from available market resources to support their identity projects (Arnould \& Thompson, 2005). However, consumer researchers have most frequently looked at the influence the marketplace has on consumers' identity projects (e.g. Arsel \& Thompson, 2011; Luedicke, Thompson, \& Giesler, 2010; Schau, Gilly, \& Wolfinbarger, 2009), while the reverse process - how consumers' identity projects influence the marketplace and general culture - is an issue that has been scarcely investigated (Scaraboto \& Fischer, 2013).

Second, observing the potential for resistance embedded in consumers' everyday practices (Certeau, 1984), CCT scholars have investigated how consumers resist by subverting the meanings of market offers (Holt, 2002; Kozinets, 2001; Thompson \& Haytko, 1997) or by appropriating marketing tools to support their own causes (e.g. Kozinets \& Handelman, 2004). Most of this research, however, does not focus on online forms of consumer activism, which have been said to significantly differ from other, more traditional forms of social movements and consumer resistance (Ward \& Ostrom, 2006).

Third, although scholars have investigated the role of consumer practices in promoting market and cultural change (e.g. Ansari \& Phillips, 2011; Humphreys, 2010a, 2010b; Thompson \& CoskunerBalli, 2007) consumer discourses have received less attention. More specifically, consumer researchers have not sufficiently explored the rhetorical strategies of online consumer activists. We posit that this is a relevant area of investigation because the discourses employed by consumer activists may help shape new collective identities, and create and disseminate new material culture items to be diffused beyond the social movement's boundaries (Harold, 2004; McAdam, 1997), potentially promoting market and cultural change.

Aiming to advance the understanding of these issues, we conducted a qualitative investigation of the Fat Acceptance Movement, an online-based movement, initiated in the United States, that connects consumer-activists who attempt to change societal attitudes about people who are fat 
(Cooper, 2009). Our main goal in this study is to investigate how consumer activists, in the context of the social fat acceptance movement, reframe market offers while pursuing identity projects, and attempting to promote market and cultural change. We draw from studies of cyberactivism and the New Social Movements theory (NSM), which suggest the importance of framing acts, to achieve our goal by focusing on the rhetorical strategies employed by consumer-activists in promoting different levels of change, varying from individual to social, and from market-specific to cultural.

Given its focus on understanding how market offers are reframed by consumer-activists, this study's contributions are threefold. First, we complement existing CCT literature by investigating how symbols, meanings, and practices available on the market are actively re-appropriated by consumer activists to serve their causes. Second, we identify the rhetorical strategies employed by consumer cyberactivists to promote individual, social, and cultural change. By doing so, we complement studies that focus on consumer practices with our perspective on consumer discourses to advance understanding of consumer resistance and activism. Finally, we connect individual identity projects to market change, advancing consumer researchers' knowledge on how consumers may initiate and promote market transformation.

Our article is organized as follows. We begin by briefly reviewing relevant literature pertaining to New Social Movements and cyberactivism, more specifically consumer online interactions, and rhetorical strategies. We believe that drawing on these three theoretical streams is valuable, given that the former two streams have made advances in explaining how consumer activists congregate online and the latter has discussed the role of persuasion in promoting change. Following the literature review, we present our research context (blogs associated with the Fat Acceptance Movement), our research methods, and our findings. We conclude by discussing the implications of our findings to consumer research.

\section{Cyberactivism and New Social Movements}

New social movements dedicated to the most diverse causes are generated, expanded, and sustained online by engaged consumers known as cyberactivists (McCaughey \& Ayers, 2003). In these movements, face-to-face interaction, protest marches, and boycotts are substituted for the dissemination of information on websites and blogs, hacking actions, e-mail emission, online petitions, and massive posting on social network pages, among other activities.

Cyberactivism is generally defined as the active engagement of individuals within informationbased networks built in computer-mediated environments (e.g. Lamberti \& Richards, 2011; McCaughey \& Ayers, 2003; Montardo \& Araújo, 2012). The Internet, by eliminating distance and time boundaries, brought new features to the process of social change. New forms of social movements occur online, and these new forms raise many questions for scholars studying activism, cyberspaces, and cultural change.

Postmes and Brunsting (2002), for example, suggest that the internet may transform social movements in two ways. First, new members and sympathizers are easily gathered to an online movement. The internet facilitates integration and allows individuals that would be outsiders or peripheral members in traditional movements to participate more actively. Second, meaning is attributed individually to the group by each participant because there is no direct influence of one member over another in deciding groups' motives, courses of action, and boundaries.

Despite being simpler that many forms of offline activism, engagement in online activism also demands time, attention, and special technical resources and skills to be effective. Online movements require from their members constant vigilance, regular searches for references and constant updating (Land, 2009). A vast amount of invisible labour is required from online activists, and, differently from traditional social movements, there is usually no organization involved in coordinating individual 
efforts online. In addition, it is difficult to determine the amount of resources available to the movement as a whole.

In addition, online movements are fluid, because their activities are embedded in members' everyday lives. Cyberactivism frequently happens when activists are at home, comfortably placed in front of their personal computers. These characteristics associate cyberactivism to more fluid forms of activism, which have been investigated by scholars working under the New Social Movement (NSM) research tradition. As Gusfield (1994) explains, these movements are "less likely to be drawn into collective actions as strikes, boycotts, pickets, or demonstrations. They occur in the myriad actions of everyday life; in micro and less public acts" (p. 64). As NSMs, which "moved away from the instrumental issues of industrialism to the quality of life issues of postmaterialism" (Pichardo, 1997, p. 412), cyberactivism tends to focus on identity and lifestyle issues. Nevertheless, political and economic goals may be sought by online activists, just like NSMs may question the purposes of industrial-societies, and the structures of governments.

A key aspect of NSMs, and, we posit, of cyberactivism, are framing processes. Alongside resource mobilization and political processes, framing has been regarded as a central aspect for understanding the evolution and nature of social movements (Benford \& Snow, 2000). Framing refers to the work of "meaning construction": "an active, processual phenomenon that implies agency and contention at the level of reality construction" (Benford \& Snow, 2000, p. 614). In other words, "framing functions in much the same way as a frame around a picture: attention gets focused on what is relevant and important" (Johnston \& Noakes, 2005, p. 2). As the authors explain, successful frames in social movements must not only say what is important, but do so in a convincing way, in order to resonate with the audience.

\section{Online consumer action}

Despite the large potential impact of cyberactivism on the market and on consumers' culture, consumer researchers know little hitherto about the multiple ways in which consumer activists gather together and influence others online. Studies on online brand communities have provided insightful findings on consumers' online interactions but this research stream is mainly concerned with communal and positive aspects of the relationships between consumers and brands (e.g. Cova \& Pace, 2006) and hence does not provide many insights about online activism - which is usually motivated by non-conformity and implies in cultural and social change. In a study of consumer activism, for example, Kozinets and Handelman (2004) borrow from the NSM paradigm to theorize about consumer movements centered on anti-consumerism organizations and activist coalitions. The authors focus specifically on the ideological aspects of anti-advertising, anti-Nike, and anti-genetically modified food consumer movements. Consumer culture theory, they propose, "will benefit from greater attention to the culture change goals of contemporary consumer movements" (Kozinets \& Handelman, 2004, p. 703).

In a more recent study, Scaraboto and Fischer (2013) provide a comprehensive review of studies that have addressed collective consumer attempts to promote market and cultural change. With the exception of Kozinets and Handelman's analysis reviewed here and Giesler's (2006) study of music downloaders' practices and their impact on the music industry, other studies have focused on consumer collective attempts to change the market that have taken place offline. In their investigation of the online Fatshionista movement, Scaraboto and Fischer (2013) focus on the triggers of consumer mobilization and at the change strategies marginalized consumers use when they want to be better served in mainstream markets. Our study extends this understanding by bringing insights on how cyberactivists draw from and reframe market offerings through the employment of rhetorical strategies in their attempts to promote self-, market-, and cultural change. 


\section{Rhetorical strategies}

Rhetorical analysis focuses on the understanding of displacements of meaning in "persuasive texts generated specifically in response to social change" assuming a "direct and dynamic relationship between rhetorical structures and the cognition and action of actors" (Suddaby \& Greenwood, 2005, p. 40), having "a very specific focus on suasion and influence" (p. 39). The object of rhetorical analysis was, originally, the oral discourses as those produced in law courts and political campaigns (Leach, 2000). With time, however, this focus has been extended to cover the study of all forms of discourse, varying from overt to covert persuasive discourses, and produced not only orally, but also in text, video, or audio format.

More than the application of rhetorical analysis as a method (for an application, see Leach, 2000), we are interested in the fundamental categories rhetorical analysts employ to understand the appeal of rhetorical texts depending on the authors' purposes, because these will be key to understanding the framing online consumer activists engage in. For the purposes of this study, we call these categories rhetorical strategies. Rhetorical strategies thus understood consist of attempts to persuade other actors to act according to one's preferences. These strategies are persuasion tools that are available to social being at all times, and they can be classified in three types, depending on the nature of the argument employed: ethos, pathos, or logos. Essentially, ethos refers to persuasive arguments that rely on establishing the credibility of the author and developing power relationships in the process. Pathos includes attempts to persuade based on emotions. Logos, in contrast, characterizes appeals to logics as a form of persuasion (for a detailed description of each rhetorical strategy, see Scaraboto, Rossi, \& Costa, 2012).

Rhetorical strategies have been observed in organizational studies to understand institutional change, technology adoption and decision making processes (e.g. Muller, Sillince, Harvey, \& Howorth, 2004; Suddaby \& Greenwood, 2005). Marketing scholars have paid attention to rhetorical strategies in investigating the effects of language and images as a persuasion tool employed by marketers (e.g. Ahluwalia \& Burnkrant, 2004; Huhmann \& Albisson, 2012), and consumer researchers have looked at the language strategies and narratives created by consumers to attribute value to their stories and meaning to their experiences (Thompson, 2004).

For scholars interested in understanding persuasion, or the influence of one individual, group, or organization over others, rhetorical strategies offer an invaluable entry point. Focusing on rhetorical strategies requires that researchers pay attention to the context in which these strategies are employed, the exigence, that is, the problem or condition addressed by a speaker through rhetorical strategies, and the audience to which attempts to persuasion are addressed (Leach, 2000). Therefore, we will be sensitized to the rhetorical strategies employed by consumer activists as we develop our understanding of their persuasive attempts.

\section{Research Context}

Fat Acceptance (FA) is a cause that has mobilized a great number of individuals in many countries, including the United States, England, and Brazil (Godoi, 2011). The ideas related to the FA movement have been disseminated on weblogs dedicated to the topic (check: Retrieved January 17, 2007, from http://www.moreofmetolove.com/resources/link_directory/category/blogroll/ for a list of blogs). Activists for Fat Acceptance use their blogs to gain self-expression, to deconstruct cultural assumptions about people who are fat, to find and offer support in escaping the oppressive obligation of being thin, and to invite society to question many of its assumptions about fat. The number of blogs dedicated to Fat Acceptance and the intensity of their activity has been noticed by traditional media (e.g. Friedman, 2008; Rabin, 2008; Wann, 2013). Several articles on the topic have been published in journals and magazines, and TV shows offered space for FA activists to debate their causes with opponents of the movement (e.g. YouTube, 2012). However, the core of the conversations around FA 
is still on the internet and, therefore, the actions of members of the FA movement can be characterized as cyberactivism.

The set of blogs dedicated to Fat Acceptance or related themes is known as fatosphere, as they represent a subset of the blogosphere - the entirety of blogs available on the internet (Cooper, 2009). According to its members, the fatosphere is "a loosely interconnected network of individual blogs, homepages and activism sites conceived with the purpose of countering weight-based discrimination through challenging social and medical misconceptions about fat people" (Richie79, 2008).

Consistent with theoretical perspectives that attribute to cyberactivism characteristics of looseness and fluidity (Gusfield, 1994), a FA blogger notes:

For years, a lot of us (myself included) have felt that 'the movement' is this nebulous thing out there - something to mention and reference, but not necessarily something to participate in; for some, it wasn't something to be proud of (Paul, 2008a).

His post also highlights the importance of the individual to online social movements: "But it's important for us to realize that each and every one of us is the movement. We are activists. We are advocates. We are the ones on the front lines every day, combating stereotypes and pushing for change" (Paul, 2008a). These and other similar messages posted to the fatosphere blogs suggest that this is a relevant cyberactivism context in which we can examine the discourses of consumers who attempt to motivate each other to engage in activism that aims to change the market, and society overall.

\section{Methodology}

Four blogs dedicated to fat acceptance were selected as source of data to this study (for a detailed description of each blog, see Appendix). These exemplars can be considered part of a group of blogs referred to as A-list (Herring et al., 2005). A-list blogs are the most widely read in a particular category of blogs. They are frequently cited in mass media; they are linked to by many other blogs, they act as filters for content related to their theme, and often have a political focus. Therefore, Ablogs are expected to be highly influential on the blogosphere and beyond.

To identify a list of A-blogs related to fat acceptance, we considered two rankings (Technorati and Google Blogs) that classify blogs according to their popularity. A preliminary selection of five blogs was submitted for evaluation by Paul, an activist at the Fat Acceptance movement who also hosts a blog on the topic. According to Paul's suggestion, one of the initially selected blogs was not properly a fat acceptance related blog and it was therefore eliminated from the sample. The blogs in our sample are: Shapely Prose (authority: 762); Big Fat Blog or BFB (authority: 186); Feed Me (authority: 92) and The F-word (authority: 246).

To collect data, we read and observed the activity in each blog of the sample. Archived posts were considered as archival data, while posts and comments generated during data collection were complemented with notes and comments by one of the authors regarding the conversation (Herring et $a l ., 2005)$ that happened in each thread. Videos, photos and other visual or audio content posted on the blogs during the observation were also collected and treated as complementary data. Data collection started in January 2008, and ended in September 2010, when one of the blogs in the sample, Shapely Prose, was terminated. Since then, two other blogs in our sample have also been closed, reflecting the dynamic nature of the blogosphere. Nevertheless, the archives for these blogs continue to be available to readers online.

There are no clear guidelines to define what participant observation accounts for when the research field is a group of weblogs. From previous studies on the blogosphere and other computermediated environments (e.g. Kozinets, 1999, 2002) we know that individuals can assume several 
levels of involvement with an online community or blog, varying from merely reading the content posted by bloggers to actually creating a blog and linking it to others. We decided on reading posts and posting comments on the blogs - an amount of participation that could provide enough familiarity with the activities, language, and culture of bloggers and readers while keeping data collection as naturalistic and unobtrusive as possible. To assure ethical research procedures, the writers of the four blogs were contacted by e-mail and their consent was asked to use their blogs' content as research data.

The analytical methodology employed in this study takes advantage of the computer mediated discourse analysis (CMDA) techniques and combines it to standard procedures for qualitative data analysis (e.g. Miles \& Huberman, 1994) in order to identify the rhetorical strategies employed by bloggers. CMDA "applies methods adapted from language-focused disciplines such as linguistics, communication, and rhetoric to the analysis of computer-mediated communication" (Herring, 2001, p. 151). While early analysis followed the coding procedures described by Miles and Huberman (1994), the use of CMDA techniques facilitated the identification of themes and patterns on the blog posts while keeping relevant the particularities of the computer-mediated communication, such as synchronicity, variation in length, insertion of links, and interactivity.

To identify the rhetorical strategies employed by bloggers and readers that post comments, a purposive sample of the posts was identified. The intention was to select posts in which bloggers reframe market offers. It is important to note that these posts are not the majority on the observed blogs, where topics vary within a large spectrum. The-F-word.org blog, for instance, classify its topics in 25 categories, ranging from legal issues to recipes. The final sample of selected posts comprised 71 pages of single-spaced text, containing 19 posts, 89 links to other posts, blogs, or websites that were also read and included in the sample when considered necessary. Each selected post generated an average of 26.8 comments from readers. Representative comments were also selected to complement the sample.

We read the posts several times to explore the uses of language, metaphors, the presence of contradictions, the threads of comments, and other rhetorical devices employed by bloggers such as claims to authority, emotional words and sentences, and appeals to reason (Young \& Foot, 2005). We then iterated between theory and data as we organized groups of codes and themes according to the main rhetorical strategies (i.e. logos, ethos, pathos). Finally, we determined different levels of intended change that best account for the rhetorical strategies employed by cyberactivists to deconstruct and reframe market offers.

\section{Findings}

The general goals of the FA movement evolve around the combat of fat stereotypes, the combat of discrimination against people who are fat (accompanied by the promotion of fat rights), and the promotion of self-acceptance and HAES (health at every size). Parallel to these goals, FA blogs are positioned as a space for non-diet discussion, and for the sharing of ideas and experiences. When focusing on posts related to market offers, the goals of the FA movement converge towards denouncing the dissemination and reinforcement of fat stereotypes by the media and other companies. By pointing to the discriminatory aspects of market offers, activists attempt to call up their audience's attention to veiled forms of fat discrimination, and to educate people about the dangers of dieting and weight loss programs. Through these posts, activists also demonstrate that they are well informed and cannot be easily deceived by the market. Finally, activists work to achieve these goals through deconstructing the arguments used by weight-loss defenders and companies, discrediting evidence that does not support the movement's goals, and writing persuasive texts to engage readers in the FA cause. 
Participants in the FA movement share several assumptions, namely: (a) people who are fat are discriminated against in most western societies; (b) the media contributes to the dissemination of representations of people who are fat as lazy, unhealthy, and a burden to health systems and society in general; (c) fat is not always bad and unhealthy; (d) diets do not work; and (e) some people will continue to be fat despite eating healthy and exercising. Acknowledging these assumptions and understanding how radically opposed to widespread cultural beliefs about fat they are is important to gain perspective when analysing the actions of bloggers and their potential to achieve cultural change.

Through denouncing and repositioning market offers on their blogs, FA activists attribute new meanings to the representation of people who are fat and to fat-related issues on the media. FA bloggers criticize industries that use a person's weight or size as a differentiating factor in their marketing policies, such as air carriers (that charge two seats to larger passengers) and insurance companies (that refuse customers if they are above a certain weight). Finally, when criticizing market offers, cyberactivists produce, compile, and disseminate information that supports the movement goals.

\section{Different levels of change}

After aggregating our analytical codes according to the three broader categories of rhetoric (i.e. logos, ethos, and pathos), we observed patterns in the use of rhetorical strategies by bloggers which are related to the type of change the bloggers intend, more so than to the individual characteristics of each blog or blogger. For example, to promote personal change, cyberactivists of the FA movement register in their blogs their individual journeys towards personal transformation. This is achieved by the use of emotional words and illustrative life episodes. In three of the four blogs we include in our sample, this strategy was employed in posts. In the other blog, participants' profiles within the blog frequently include life stories and employ a pathos appeal to tell their journeys toward acceptance. Through telling these stories, authors create ethical appeals that convey to readers their credibility and expertise on the matters discussed in the movement.

As they experience personal change and report it in their blogs, these bloggers start to offer arguments, support, and motivation to their readers to also pursue and promote change. Because bloggers might find it difficult to characterize the members of their audiences, logical arguments prevail here, and bloggers supply their imagined audiences with reasonable claims and proofs (evidences) supporting those claims with the intention to inspire and persuade new followers. This was observed across all four blogs in our sample. Additionally, the activists combine emotional and ethical arguments to call other members to promote broader, social change, in all blogs sampled.

The following sections detail the rhetorical strategies employed by bloggers when arranging and presenting information about market offers in a reframed and persuasive way, and describe how these strategies vary for each level of intended change.

\section{"I was blind, but now I see" (the activist changes)}

As the consumer activism studied by Kozinets and Handelman (2004), cyberactivism is related to an individual's social conscience of something new, of a revelation. This revelation, or "moment of truth" (p. 695), happens when consumers leave their old assumptions behind and begin to change. Individual change is associated with identity change, and individuals work to develop a new identity, one that is closer to that of the activist group.

The notion of personal change carries a paradox for activists on the FA movement. Usually, people who are fat have tried to transform their bodies to get thinner through diverse ways including diets, exercise, and even surgery. However, what the movement asks for is exactly the opposite of the transformation imposed on people who are fat by society at large. Fat Acceptance requires selfacceptance from its members: it invites participants to accept their bodies the way they are, and change their minds about what it means to be fat. This shift of ideas, beliefs, and perspective about fat guides 
the activists' identity projects and is reflected in their blogs. Reframing market offers helps bloggers mark these personal changes. Frequently, FA activists present a marketer/product as something they liked before. The bloggers then describe the moment when they realize that the referred marketer or product is actually not fat-friendly, and therefore should no longer be appreciated or sponsored, as illustrated by the following excerpts: "There was a time when I kind of respected chef Jamie Oliver. I liked his style and attitude towards food and recipes. Then he started undertaking a cause near and dear to many a moneygrabber's heart: OBESITY CRISIS!!!” (Paul, 2008b).

I really like Pixar, and I think their films' messages of self-improvement are usually on spot. But frankly, I find the premise of this film [Wall-e] to be neither entertaining nor positive. I also find it ironic that while Disney (who owns Pixar) says its working to promote diversity amongst its workforce, it's simultaneously contributing to a culture that stigmatizes these differences (The-F-word.org, 2007).

By presenting their arguments in this way, activists reveal the particular reasons why they believe a market offer should be criticized. What our data shows here is in contrast with Kozinets and Handelman's (2004) observation that most consumer movements immediately and readily assume the existence of "a corporate elite as consumer activists' adversaries" (p. 697). FA activists feel the need to carefully justify, in their texts, why marketers should be the ones to blame - or to attack - if the changes desired by the movement are to be achieved. However, these blog posts also suggest that being part of the movement involves adopting a new perspective not only of one's body and sense of self, or the specific marketers bloggers target in their texts, but also of market offers in general. The posts appeal to readers' emotions, and attempt to provoke in them the same feelings of deception, betrayal, disappointment. Once one adopts the lenses of the movement, everything is put under scrutiny, including companies, brands, products, and celebrities that were once unquestionably appreciated. Posts like these remind readers that companies' offers or messages may turn out to be discriminatory or offensive to fat people at any point in time, and in that case, the corporation justifiably becomes the opponent (Kozinets \& Handelman, 2004). Therefore, FA activists should be constantly alert to the need to rethink their assumptions about market offers, and to notice violations and offensive marketing acts. For instance, when Old Navy stopped carrying plus-sized clothes in their stores, Kate wrote:

I also like to support stores that offer plus sizes even if I don't need them. Old Navy used to be one of those. Now it's not, and I have a dilemma. I can still shop at Old Navy, because their regular sizes are pretty generous, and I'm not all that big. But do I want to, knowing they've just issued a huge slap in the face to everyone who can't? To plenty of people who'd been loyal customers over the years? To a $\$ 27$ billion market?.... So I'm done with Old Navy.... I don't need to support a company that disrespects my bigger sisters (Harding, 2007a).

In this post, Kate uses the narrative format, which allows readers to follow her developing rationale about the company. While she tells a story of personal change, Kate educates her readers by offering them an example of how to link existing beliefs and preferences to the radical assumptions of the movement. She also appeals to readers' emotions by portraying the company as a disrespectful traitor capable of slapping loyal consumers on the face.

In telling their stories, the blogger-activists also employ ethical appeals and present evidences in support of their authority to criticize and reframe market offers. When posting about the new Weight Watchers slogan "Diets don't work, Weight Watchers does," (Harding, 2007b) Kate describes her own experience with the company as a proof of her authority to discredit Weight Watchers' communication strategy: "I've been hearing that argument for ages - hell, I made that argument while I was on Weight Watchers — and I'm sure it was around before I was born" (Harding, 2007b).

She concludes with more evidences to legitimate her criticism:

Well, as someone who was unwittingly giving Weight Watchers money until a few months ago — because I completely forgot I'd signed up for their online program again ... - I'm here to 
tell you I never got the magic secret. What I got for my money was access to a diet plan; no more, no less (Harding, 2007b).

Frequently, stories shared by readers on comments endorse the stories and arguments presented by bloggers. However, not all the meanings offered by bloggers are adopted by readers without second thought. Here we see that the distinction between activists and general consumers identified by Kozinets and Handelman (2004, p. 698) in their data does not correspond directly to a distinction between bloggers as being activists and their audiences as being general consumers waiting to be "enlightened" or "converted". When posting about a TV design show, blogger Rachel criticizes the show's choice of a woman who lost 180 pounds as deserving of a home makeover and moves the reader along to her conclusion: "The message here is clear: Only people who lose weight are "deserving' of public recognition and gifts" (Rachel, 2008a). A reader perceives the forced pace of that argument and replies, referring to other episodes of the same show: "Just because something hurts doesn't mean it's unfair.... Why read the weight-loss episode as a referendum on fatness, when the other episodes are not referendums on military service, procreation, etc.?" (Nina, 2008).

Rachel attempted to employ a logic appeal (logos), but the comment quoted above suggests that the reader identified the hasty generalization on Rachel's argument. Had the reader been persuaded to adopt the lenses of the movement, she could employ the same reasoning used by the blogger to interpret the show as loaded of fat avoidance cues. Given the debatable nature of personal opinions, activists go beyond tales of personal experience and employ other rhetorical strategies to break resistance and persuade less credible readers. In the following section we identify the rhetorical strategies employed by activists to advance to the next level of change and motivate readers into the adoption of a new perspective on market offers.

\section{"I want that for all of you" (changing the audience)}

Empathy between writer and readers plays a large role in promoting change at the audience level. Manifestations such as "That's exactly what I was thinking, MichMurphy!" (Sevendayswonder, 2008), and I don't feel so alone anymore are frequent among the comments to posts by FA activists. We also found that all bloggers in our sample constantly link to one another and to other FA websites, leading the reader through a preferred path within the fatosphere. This practice conveys to the audience that they are not merely reading the opinion of a blogger, but becoming involved in something that is more structured, bigger, and more relevant. The reaction of the audience includes expressions such as I am more than glad to find places online where discussion of weight loss is not allowed; It is a huge breath of fresh air; or I am so glad you found us, and that we found you. The more, the merrier; and I don't feel so alone anymore. I was ready to fight for Fat Acceptance by myself if I had to, but I really didn't want to have to.

While feeling part of the movement is a first step towards change, other transformations are much harder to achieve. Bloggers are constantly reminding their audiences about the perils of deeply rooted social practices and cultural beliefs. The deconstruction of market offers is used as means to illustrate the need for reflection. Indeed, the observed bloggers are very overt in their intention to promote critical thinking and reflection in their audience. Features such as Links to make you think (Feed Me) and Find your voice project (linked to at The-F-word.org) are combined to posts that use the imperative voice and appeals to logic to instigate readers, like in this text written by Fillyjonk (2008):

In fact, don't buy the sign.... Don't buy it; it doesn't apply to you. There will always be messages telling you that your body's beautiful individual idiosyncrasies are "issues" and "problem areas" that need to be cured. I want to be able to march right up to them and say 'I don't suffer from it; I love it'. I want that for all of you, too.

This example also demonstrates another strategy frequently employed by bloggers to motivate the audience into change. When Fillyjonk states "I want that for all of you, too" (Fillyjonk, 2008) she directs her efforts to the wellness of all the readers. She amplifies the scope of her change goals and 
indicates she is looking for benefits to everyone, not only to herself. In yet another logic argument, the posts suggest that if she can achieve the change, everyone else should be able to do so.

When focusing on industries and companies, bloggers collect information disseminated on the internet and employ logical and ethical arguments to reframe the positioning of market offers. The use of evidences and logical reasoning to legitimate criticism of the diet industry, for instance, is illustrated by the following quotes: "Szwarc goes on to give a brief background of the [dieting] company's extensive history in the courts, most notably that of civil lawsuits citing the company made false claims about its weight loss program" (The-F-word.org, 2008a).

Do me a favor. Go click on the "Success Stories" section on their [Weight watchers] website. I won't link, but go ahead, I'll wait. Do you see that asterisk underneath the "after photos"? The one next to the words "Results not Typical." Yeah. Weight Watchers, according to their website, is "unique." It's different from all those other diet plans — in fact, it's not one! ... But for some strange, inexplicable reason, they still have to include the same disclaimer as every other diet program that touts its success with pictures of former fatties (Harding, 2007b).

Once more, the audience is presented or guided through evidence in order to promote critical thinking. In contrast, when the posts are dedicated to deconstruct media products, there is more space for individual interpretation while logical arguments and the use of reasoning are frequently undermined by fallacies and emotional words. When describing the fat prejudice she perceives on a TV show, Rachel quotes the show host and writes exasperated:

"You are truly a deserving person," says Vern to Flavia at the closing. "You lost 180 pounds and now you are just as beautiful on the outside as you are on the inside". Oh, my... Where do I begin? Maybe I should start with the inherent wrongness of elevating weight loss next to godliness? (The-F-Word.org, 2008a).

In a similar post presenting a new reading of a media product, it is possible to notice the flaws in Rachel's argument about a movie intended to be fat-friendly:

It comes as little surprise when the film reveals later that Maggie's father died from diabetes, no doubt, caused by his fatness. In real life, Burris' father died of an asthma attack, so I question the motives of producers in arbitrarily changing his cause of death to a disease negatively, commonly and often erroneously associated with obesity (Rachel, 2008b).

In her post, Rachel acknowledges the attempt of the movie to be positive about fat, given that the main role is that of a fat teenager who becomes the school queen. Despite praising the movie in general, the blogger points to several discriminatory aspects of it. What posts like these suggest is that the authors invite readers to change their perspective about companies, products, and media while abandoning previous assumptions about fat. The audience is invited to react, to defend themselves, to be critical of market offers and to question statements about people who are fat. In another post, Paul criticizes an insurance company for reinforcing the fight against obesity. Responses to these blog posts indicate readers' dissatisfaction with other companies in the same industries and also suggest their willingness to change, as explicated by a reader: "Great, I was about to enrol for health coverage with BCBS. Might have to rethink that now" (Sarahj, 2008).

Usually, cyberactivists have no more than a vague idea of who are the members of their audiences. This is because the portion of readers who comment on a blog is frequently small and may not represent the multiplicity of views held by the whole set of readers (Ayers, 2003). Nevertheless, blogger-activists are clear in their intentions to reach as many readers as possible in order to spread the movement word, as Kate suggests on one of her posts:

I was waiting to post on this until today, because traffic is so much lower on weekends, but I forwarded Ginviren's note to a few people, and Harriet, Rachel, and Paul, among others, have all written more about how disturbing the entire site is (Harding, 2008a). 
Even dealing with a diffuse and imprecise audience, FA activists employ specific rhetorical strategies to promote critical thinking in their readers. The immediate intended consequence is a shift of perspective in individuals' opinions, beliefs and practices, but these blogger-activists also aim for changes at higher levels.

\section{“An uphill battle" (changing the market, changing the culture)}

Besides promoting change among their audiences, cyberactivists also use their blogs to call readers into action. When a company or situation is presented as discriminatory, offensive, or prejudicial against fat people, readers are compelled to manifest themselves. This genre of posts usually receives a high number of responses. Many of the readers who comment on such posts report their actions related to the topic, as the following comments illustrate: "I put my comment on there directing them to love themselves and search out better sites. I think we all should do the same" (Vivelafat, 2008). "I will refer this very stupid writer to such things as 'World War II' 'World War I' and 'The Black Plague' just to get things rolling" (ChiaraG, 2008).

The specific post these readers commented on discussed an article at a Procter \& Gamble $(\mathrm{P} \& \mathrm{G})$ website where dieting tips were given to teenagers. Discussions of this article were posted on all the blogs sampled in our study. The outcome of such discussions was that the article was removed from the website and $\mathrm{P} \& \mathrm{G}$ sent its apologies to bloggers and to all consumers affected by the article. Such an achievement, no matter how small a change it may represent in the overall market, demonstrates how cyberactivists can effectively mobilize their audiences into changing the market.

Emotional words are also employed by bloggers to highlight the negative aspects of the company/market offer being criticized. The combination of emotional tone with ethical arguments is evidenced by the presentation of selected facts about a company or offer and aims at moving audiences into action. Rachel's post on the controversial Procter \& Gamble article is an example of the rhetorical strategies employed in such situations:

What's even more sad (sic) is that P\&G has partnered with Hearst Magazines, so that the site and potentially harmful messages like this are prominently featured on Seventeen.com, CosmoGIRL.com and Teenmag.com, which collectively reach 1.5 million unique users per month. Apparently making girls feel bad about themselves and their bodies is mutually beneficial for these two companies (The-F-Word.org, 2008b).

Rachel goes on and offers her audience more information supporting her argument by linking to other bloggers who discussed the topic. This case is also an example of the typical posts written by this blogger, in which she offers detailed contact information for the criticized firm and orientations for readers as to how to engage in proper manifestations:

Contact information to voice complaints is available after the jump... [P\&G contact information]. Here are the so-called "experts" behind the site.... Address snail mail letters any or each of the following.... Suggestions on how to phrase letters of complaint can be found here. Remember: it's important to express and articulate your concerns and outrage, but ranting vitriolic letters are often highly ineffective (The-F-Word.org, 2008b).

Concerning another highly debated theme in the FA movement - the weight loss industry - Paul denounces Weight Watchers as having co-opted FA movement language. The company's new slogan Diet's don't work. Weight Watchers do. infuriated FA bloggers. Besides linking to other bloggers who posted on the theme, Paul writes:

Instead of a lengthy rant about how this is a travesty and points out the failings of our movement thus far, let's just take action instead. Let's make up one-page flyers to combat this misleading and manipulative advertising. Let's distribute them where these ads are located - and, outside of Weight Watchers locations. Let's combat this with the truth. Here are three PDFs I put together. Print them up, adapt them... knock yourself out (Paul, 2007). 
Ultimately, Paul and the other bloggers are providing readers with tools to combat fat discrimination and act to promote individual and collective change. However, market offers are deconstructed and reframed by bloggers in their quest against fat discrimination. Fighting against companies is not the ultimate goal of these cyberactivists, rather to criticize companies' hidden intentions and discriminatory practices is a starting point to achieve their goal of broader social change. Topics that include calls for action against companies or products generally spread quickly at the blogosphere and reverberate in traditional media. By acting online and offline against companies and offers that are negatively perceived, FA activists catch media attention and also attract more adherents to the movement. Fat acceptance activists recognize their goals are of great magnitude and celebrate every small change achieved, like the following quotes suggest:

So, one diet company has fallen - hoorah - but hundreds more persist and new get-thin-quick plans spring up every day. Until we eradicate a disordered and poorly informed culture in which only a narrow weight definition of acceptable exists, the national tide against dieting will never fully turn (The-F-Word.org., 2008c).

Have I just given entirely too much thought to a friggin' TV show? Of course. One episode of Doctor Who is hardly going to be seen as a watershed moment for fat rights. But it was a watershed moment for me as a consumer of pop culture, because it was literally the first time in my life I'd seen a TV show handle the topic of fat without once making me feel like I'd been slapped in the face (Harding, 2008b).

As these quotes suggest, not only successful protests, like the one directed at $\mathrm{P} \& \mathrm{G}$, but also celebrations of positive market offers (as the TV show Kate refers to) bring motivation to cyberactivists, reinforce the collective identity of the movement and suggest that their cause may be achieved through some cooperative effort.

\section{Discussion}

Our study offers an examination of the rhetorical strategies employed by online consumer activists to achieve different levels of change through reframing market offers in their blogs. We found that consumers present their personal stories of change to advance their identity projects and develop a collective identity among members of an online movement. Among other themes, consumer activists discuss market offers to promote reflection among their audience and to invite readers into sharing their own experiences and acting to promote the changes they want to achieve at the personal, market, and cultural levels.

Although FA bloggers acknowledge when companies offer a fat-friendly product or approach, they are ready to identify, amplify, and reverberate the discriminatory practices of companies towards people who are fat. Given that the goals of an online social movement tend to be broad and everchanging, the way cyberactivists' build their texts can be better understood in relation to the type of change they are trying to reach in each post, that is, through understanding the persuasive attempts of the texts they create. Figure 1 summarizes our findings, presenting the different rhetorical strategies employed by bloggers in their texts when reframing market offers to promote various types of change: 

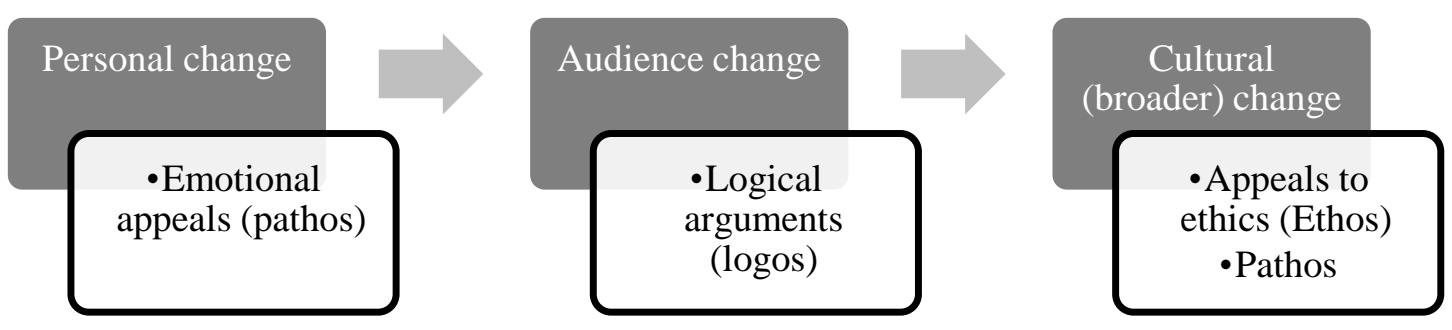

Figure 1. Levels of Change and Rhetorical Strategies.

Our findings suggest the following dynamic. In the early stage of activism, a blogger will reframe market offers as s/he tells a story of personal change. Appeals to readers' emotions and claims to authority are common at this stage, as bloggers are still working on their own identity project of self-acceptance, but also aiming to establish their credibility as legitimate members of the movement, and hoping to gather an audience of empathizing readers. Brands, products, and companies are usually portrayed as the object of a shift in mindset, one that allows the blogger to see the true intentions, or nature, of marketers. Usually, the new mindset is a more critical one, and this shift is supported by emotional accounts of revelatory personal experience.

Our first insight is that these accounts, combining emotional personal stories with ethical appeals, may accelerate the shift in meaning of a product or brand (usually from positive or neutral to negative) for other consumers. This process is further accelerated when bloggers start to produce persuasive texts aimed at convincing their readers to change. In seeking to justify or defend such dramatic alterations in attitude and behavior as those promoted by the Fat Acceptance movement, bloggers need to construct their arguments in a manner consistent with that of the status quo. The prevalent view regarding fat in society portrays obesity as an epidemic with serious health consequences. This view is supported by numerous official sources of information, statistics, and appeals to common sense. Mirroring this approach, one way in which bloggers attempt to persuade readers embedded in this scenario to change is through appeals to logic. Bloggers offer links to scientific studies debunking the obesity epidemic, question correlations between fat and diseases, devalue positive associations with weight loss, and criticize market offers that ignore these counterarguments. We find that, through logic appeals, bloggers scrutinize marketing messages as to deconstruct their original persuasive arguments. Pointing to flaws in those persuasive messages, bloggers are able to create logic appeals in favor of the Fat Acceptance goals.

Finally, while FA activists are experiencing and promoting change at the individual level, their ultimate goal is to change societal attitudes toward people who are fat. This is a broader level of change, and bloggers resort to multiple forms of rhetorical strategies in their attempts to promote desired cultural change. Most bloggers in our sample have a high level of education and are likely aware of the role of market offers in influencing culture. Therefore, we posit, these bloggers target market offers hoping to capitalize on the attention and to affect these companies, brands, and products. Here, emotional appeals, or pathos are employed by bloggers to create a common sense of identity with their audience and call them to action against market practices perceived as negative. Ethical appeals are used to reassure readers of the reliability of the blogger as a participant in the FA movement, as someone who is entitled to guide them through promoting broader change. These are evident in the usage of credible, reliable sources by bloggers, and in their acknowledging the difficulties implied in achieving the desired change.

These findings advance our understanding of how consumers' identity projects influence the marketplace and general culture. We demonstrate that, convergent with the predictions of the new social movement theory, cyberactivists focusing on lifestyle themes constantly refer to market offers and media as producers and maintainers of the lifestyle the movement tries to transform. However, 
differently from individuals behind consumer complaint websites (Ward \& Ostrom, 2006) and the consumer activists investigated by Kozinets and Handelman (2004), cyberactivists, as the FA activists we studied, were not specifically targeting marketers, but did so in order to amplify their word, convince more people to adopt their perspective, and promote individual and cultural change. This has important consequences for theorizing about consumer activists, since it broadens the phenomena of interest for marketer researchers to other types of movements and change attempts, including those of individual and cultural levels, even if these do not focus on marketers and consumption phenomena at first sight. Second, by focusing on online forms of consumer activism, our study expands on how this form of activism significantly differs from other, more traditional forms of social movements and consumer resistance (Ward \& Ostrom, 2006). We demonstrate that online consumer activism is closer to the new social movements, representing a form of cyberactivism, as they use technology and the properties of the web to mobilize supporters and resources.

Finally, our findings complement studies that look at the practices of consumer activists by calling attention to their discourses. We demonstrate that the rhetorical strategies of consumer activists help them shape their individual and collective identities, and reframe market offers in ways that are convincing and resonate with their audiences.

\section{Managerial implications}

This study also informs us about the way bloggers employ rhetorical strategies to present market offers to their audiences and invite readers to engage in deep thought about companies and products. Cyberactivists collect dispersed facts about a particular company or product and aggregate them in persuasive posts to support their arguments. Cyberactivist bloggers are perceived as being committed to the collective good, representing legitimacy and authority to their audiences. Therefore what these bloggers write (and how they write) about market offers may motivate readers to reflect and react in a way traditional media cannot do.

If marketers and companies get caught under the fire of online activists, it is because they offer a common reference that can be used by movement adherents to develop and strengthen their collective identity. By criticizing and protesting against a company or industry, cyberactivists direct their efforts towards a visible target. Small victories in this direction motivate these activists to keep working in the promotion of social and cultural changes that are their ultimate goals. These observations suggest that marketers should be aware of online movements and the implication of companies' activities and offers to these individuals engaged in social causes.

From a managerial point of view, the persuasive process we identify here is difficult to reproduce strategically, since most of the narratives and stories concern consumers' personal experiences and those are going to be specific to certain groups and cultures. For marketing managers to succeed in attracting this segment of clients, or at least to suffer less damage from activists' reframing acts, they must develop a full understanding of the consumer activist's group culture. Successful marketing strategies may result in the transferring of the group culture to mainstream (Thompson \& Coskuner-Balli, 2007) without negative consequences, and marketers may develop solid and long-lasting relationships with a group of deeply involved consumers.

\section{Limitations and Future Studies}

This study has limitations that suggest directions for future research. First, because blogs are ultimately personal spaces and reign of their authors, most bloggers hold a rigorous policy of comments and opinions that are opposite to those of the activists may not be represented in this study. Even companies' feedback to posts relating to their offers may have been censored by bloggers. Future studies using depth interviews could deepen insight into activists' motivations to write about market offers and into eventual responses given by companies. Second, the blogs observed in this study may 
not be representative of the whole FA movement. No conflicts were evident among the four bloggers and they shared information sources, frequently blogged about the same topics, and linked to each other frequently. It is likely that a broader sample of blogs inside the movement would represent the use of different approaches to reframe market offers. Finally, we could only make inferences about the persuasive effect of bloggers' rhetorical strategies based on readers' comments to posts. Future research should be directed to the investigation of the persuasive effect of rhetorical strategies employed by cyberactivists on their audiences.

\section{References}

Ahluwalia, R., \& Burnkrant, R. E. (2004). Answering questions about questions: a persuasion knowledge perspective for understanding the effects of rhetorical questions. Journal of Consumer Research, 31(1), 26-42. doi: 10.1086/383421

Ansari, S., \& Phillips, N. (2011). Text-me! New consumer practices and change in organizational fields. Organization Science, 22(6), 1579-1599. doi: 10.1287/orsc.1100.0595

Arnould, E. J., \& Thompson, C. J. (2005). Consumer culture theory (CCT): twenty years of research. Journal of Consumer Research, 31(4), 868-882. doi: 10.1086/426626

Arsel, Z., \& Thompson, C. J. (2011). Demythologizing consumption practices: how consumers protect their field-dependent identity investments from devaluing marketplace myths. Journal of Consumer Research, 37(5), 791-806. doi: 10.1086/656389

Ayers, M. D. (2003). Comparing collective identity in online and offline feminist activists in cyberactivism: online activism in theory and practice. In M. McCaughey \& M. D. Ayers, (Eds.), Cyberactivism: online activism in theory and practice (pp. 145-164). New York: Routledge.

Benford, R. D., \& Snow, D. A. (2000). Framing processes and social movements: an overview and assessment. Annual Review of Sociology, 26, 611-639. doi: 10.1146/annurev.soc.26.1.611

Certeau, M. de (1984). The practice of everyday life (S. Rendall, Trans.). University of California Press: Berkeley. (Original work published 1980)

ChiaraG. (2008, March 17). Quick hit: let P\&G know what you think of their website for girls [Web $\log$ comment]. Retrieved from http://kateharding.net/2008/03/17/quick-hit-let-pg-know-whatyou-think-of-their-website-for-girls/

Cooper, C. (2009). Fat lib: how fat activism expands the obesity debate. In L. Monaghan, L. Aphramor, \& E. Rich (Eds.), Expanding the Obesity Debate (pp. 164-191). London: Palgrave.

Cova, B., \& Pace, S. (2006). Brand community of convenience products: new forms of customer empowerment - the case "my Nutella the community". European Journal of Marketing, 40(9/10), 1087-1105. doi: 10.1108/03090560610681023

Fillyjonk. (2008, March 6). What's your problem? [Web log post]. Retrieved from http://kateharding.net/2008/03/06/whats-your-problem/

Fournier, S. (1998). Special session summary consumer resistance: societal motivations, consumer manifestations, and implications in the marketing domain. Advances in Consumer Research, 25, $88-90$.

Friedman, E. (2008, January 23). Bloggers preach 'fat acceptance'. ABC News. Retrieved from http://abcnews.go.com/Technology/OnCall/story?id=4173879 
Giesler, M. (2006). Consumer gift systems. Journal of Consumer Research, 33(2), 283-290. doi: $10.1086 / 506309$

Godoi, M. R. (2011). Corpos femininos volumosos e estética: discursos contra-hegemônicos sobre beleza em blogs na internet. Movimento, 17(3), 153-173. Retrieved from http://seer.ufrgs.br/Movimento/article/view/20972

Goodwin, J., \& Jasper, J. M. (2009). The social movements reader: cases and concepts (2nd ed.). Oxford, UK: Willey-Blackwell.

Gusfield, J. R. (1994). The reflexivity of social movements: collective behaviour and mass society theory revisited. In E. Larana, H. Johnston, \& J. R. Gusfield (Eds.), New social movements: from ideology to identity (pp. 58-78). Philadelphia: Temple University Press.

Harding, K. (2007b, December 31). Oh, mackereally? [Web log post]. Retrieved from http://kateharding.net/2007/12/31/oh-mackereally/

Harding, K. (2007a, April 30). We want your money, but not if we have to look at you [Web log post]. Retrieved from http://kateharding.net/2007/04/30/we-want-your-money-we-just-dont-want-tohave-to-look-at-you/

Harding, K. (2008b, April 6). Adipositivity (and Doctor WhoSpoilers) [Web log post]. Retrieved from http://kateharding.net/2008/04/06/adipositivity-and-doctor-who-spoilers/

Harding, K. (2008a, March 17). Quick hit: let P\&G know what you think of their website for girls [Web log post]. Retrieved from http://kateharding.net/2008/03/17/quick-hit-let-pg-know-whatyou-think-of-their-website-for-girls/

Harding, K. (2010, January 31). We are the boss of you [Web log post]. Retrieved from http://kateharding.net/2010/01/

Harold, C. (2004). Pranking rhetoric: culture jamming as media activism. Critical Studies in Media Communication, 21(3), 189-211. doi: 10.1080/0739318042000212693

Harriet. (2007, June 29). Who doesn't want to lose 20 pounds? [Web log post]. Retrieved from http://harrietbrown.blogspot.com.br/2007/06/who-doesnt-want-to-lose-20-pounds.html

Herring, S. C. (2001). Computer-mediated discourse. In D. Schiffrin, D. Tannen, \& H. E. Hamilton (Eds.), The handbook of discourse analysis (pp. 612-634). Oxford: Blackwell.

Herring, S. C., Kouper, I., Paolillo, J. C., Scheidt, L. A., Tyworth, M., Welsch, P., Wright, E., \& Yu, N. (2005, January). Conversations in the blogosphere: an analysis "from the bottom up". Proceedings of the Hawaii International Conference on System Sciences, Big Island, Hawaii, USA, 38.

Hollenbeck, C. R., \& Zinkhan, G. M. (2006). Consumer activism on the internet: the role of anti-brand communities. Advances in Consumer Research, 33, 479-485.

Holt, D. B. (2002). Why do brands cause trouble? A dialectical theory of consumer culture and branding. Journal of Consumer Research, 29(1), 70-90. doi: 10.1086/339922

Huhmann, B. A., \& Albinsson, P. A. (2012). Does rhetoric impact advertising effectiveness with liking controlled? European Journal of Marketing, 46(11/12), 1476-1500. doi: $10.1108 / 03090561211259943$

Humphreys, A. (2010b). Megamarketing: the creation of markets as a social process. Journal of Marketing, 74(2), 1-19. doi: 10.1509/jmkg.74.2.1 
Humphreys, A. (2010a). Semiotic structure and the legitimation of consumption practices: the case of casino gambling. Journal of Consumer Research, 37(3), 490-510. doi: 10.1086/652464

Johnston, H., \& Noakes, J. A. (Eds.). (2005). Frames of protest: social movements and the framing perspective. Lanham, Maryland: Rowman \& Littlefield Publishers.

Kates, S. M. (2002). The protean quality of subcultural consumption: an ethnographic account of gay consumers. Journal of Consumer Research, 29(3), 383-399. doi: 10.1086/344427

Kozinets, R. V. (1999). E-tribalized marketing? The strategic implications of virtual communities of consumption. European Management Journal, 17(3), 252-264. doi: 10.1016/S02632373(99)00004-3

Kozinets, R. V. (2001). Utopian enterprise: articulating the meanings of star trek's culture of consumption. Journal of Consumer Research, 28(1), 67-88. doi: 10.1086/321948

Kozinets, R. V. (2002). Can consumers escape the market? Emancipatory illuminations from burning man. Journal of Consumer Research, 29(1), 20-38. doi: 10.1086/339919

Kozinets, R. V., \& Handelman, J. M. (2004). Adversaries of consumption: consumer movements, activism and ideology. Journal of Consumer Research, 31(3), 691-704. doi: 10.1086/425104

Lamberti, A. P., \& Richards, A. R. (Eds.). (2011). Complex worlds: digital culture, rhetoric and professional communication. Amityville, NY: Baywood.

Land, M. (2009). Networked activism. Harvard Human Rights Journal, 22, 205-243. Retrieved from http://harvardhrj.com/wp-content/uploads/2009/09/land.pdf

Leach, J. (2000). Rhetorical analysis. In M. W. Bauer \& G. Gaskell (Eds.), Qualitative researching with text, image, and sound: a practical handbook (pp. 207-226). London: Sage Publications.

Luedicke, M. K., Thompson, C. J., \& Giesler, M. (2010). Consumer identity work as moral protagonism: how myth and ideology animate a brand-mediated moral conflict. Journal of Consumer Research, 36(6), 1016-1032. doi: 10.1086/644761

McAdam, D. (1997). Culture and social movements. In E. Larana, H. Johnston, \& J. R. Gusfield (Eds.), New social movements: from ideology to identity (pp. 36-57). Philadelphia: Temple University Press.

McCaughey, M., \& Ayers, M. D. (2003). Cyberactivism: online activism in theory and practice. New York: Routledge.

Miles, M., \& Huberman, M. (1994). Qualitative data analysis: an expanded source book. Thousand Oaks, CA: Sage.

Montardo, S. P., \& Araujo, W. F. (2012). Performance e práticas de consumo online: ciberativismo em sites de redes sociais. In P. R. Puhl \& J. A. Saraiva (Orgs.), Processos culturais e suas manifestações (pp. 116-141). Novo Hamburgo: Feevale

Muller, F., Sillince, J., Harvey, C., \& Howorth, C. (2004). A rounded picture is what we need: rhetorical strategies, arguments, and the negotiation of change in a UK hospital trust. Organization Studies, 25(1), 75-93. doi: 10.1177/0170840604038181

Muñiz, A. M., Jr., \& Schau, H. J. (2005). Religiosity in the abandoned apple newton brand community. Journal of Consumer Research, 31(4), 737-347. doi: 10.1086/426607

Nina. (2008, January 31). Re: Vern Yip shows his true colors [Web log comment]. Retrieved from http://the-f-word.org/blog/index.php/2008/01/19/vern-yip-shows-his-true-colors/ 
Paul. (2007, December 26). Weight watchers co-opts our language [Web log post]. Retrieved from http://www.bigfatblog.com/weight-watchers-co-opts-our-language

Paul. (2008b, January 17). Jamie Oliver's scare tactics [Web log post]. Retrieved from http://www.bigfatblog.com/jamie-olivers-scare-tactics-updated

Paul. (2008a). Re: Why you should be at the think tank [Web log comment]. Retrieved from http://www.bigfatblog.com/why-you-should-be-think-tank

Penaloza, L., \& Price, L. L. (1993). Consumer resistance: a conceptual overview. Advances in Consumer Research, 20, 123-128.

Pereira, S. J. N., \& Ayrosa, E. A. T. (2012). Between two worlds: an ethnographic study of gay consumer culture in Rio de Janeiro. Brazilian Administration Review, 9(2), 211-228. doi: $10.1590 /$ S $1807-76922012000200006$

Pichardo, N. A. (1997). New social movements: a critical review. Annual Review of Sociology, 23, 411-430. doi: 10.1146/annurev.soc.23.1.411

Postmes, T., \& Brunsting, S. (2002). Collective action in the age of the internet: mass communication and online mobilization. Social Science Computer Review, 20(3), 290-301. doi: $10.1177 / 089443930202000306$

Rabin, R. C. (2008, January 22). In the fatosphere, big is in, or at least accepted. The New York Times. Retrieved from http://www.nytimes.com/2008/01/22/health/22fblogs.html

Rachel. (2008a, January 22). Re: Vern Yip shows his true colors [Web log comment]. Retrieved from http://the-f-word.org/blog/index.php/2008/01/19/vern-yip-shows-his-true-colors/

Rachel. (2008b, January 15). Re: Blonsky shines; Queen-Sized disappoints [Web log comment]. Retrieved from http://the-f-word.org/blog/index.php/2008/01/15/

Richardson, R. (2009, May 11). Bad ingredient [Web log post]. Retrieved from http://the-fword.org/blog/index.php/2009/05/11/

Richie79. (2008, April 4). Re: Fatosphere in wired [Web log comment]. Retrieved from http://www.bigfatblog.com/fatosphere-wired

Sandlin, J. A., \& Callahan, J. L. (2009). Deviance, dissonance, and détournement: culture jammers' use of emotion in consumer resistance. Journal of Consumer Culture, 9(1), 79-115. doi: $10.1177 / 1469540508099703$

SarahJ. (2008, March 19). Re: Well, be good [Web log comment]. Retrieved from http://bigfatblog.com/well-be-good

Scaraboto, D., \& Fischer, E. (2013). Frustrated fatshionistas: an institutional theory perspective on consumer quests for greater choice in mainstream markets. Journal of Consumer Research, 39(6), 1234-1257. doi: 10.1086/668298

Scaraboto, D., Rossi, C. A. V., \& Costa, D. (2012). How consumers persuade each other: rhetorical strategies of interpersonal influence in online communities. Brazilian Administration Review, 9(3), 246-267. Retrieved from http://www.scielo.br/pdf/bar/v9n3/a02v9n3.pdf. doi: $10.1590 / \mathrm{S} 1807-76922012000300002$

Schau, H. J., Gilly, M. C., \& Wolfinbarger, M. (2009). Consumer identity renaissance: the resurgence of identity-inspired consumption in retirement. Journal of Consumer Research, 36(2), 255-276. doi: $10.1086 / 597162$ 
Schouten, J. W., \& McAlexander, J. H. (1995). Subcultures of consumption: an ethnography of the new bikers. Journal of Consumer Research, 22(1), 43-61.

Sevendayswonder. (2008, March 19). Re: Well, be good [Web log comment]. Retrieved from http://bigfatblog.com/well-be-good

Suddaby, R., \& Greenwood, R. (2005). Rhetorical strategies of legitimacy. Administrative Science Quarterly, 50(1), 35-67. doi: 10.2189/asqu.2005.50.1.35

The-F-Word.org. (n.d.a). About us [Web log post]. Retrieved from http://the-fword.org/blog/index.php/about-the-site/

The-F-Word.org. (n.d.b). Comments policy [Web log post]. Retrieved from http://the-fword.org/blog/index.php/comments-policy/

The-F-Word.org. (2007, November 1). Pixar joins in on fat-bashing [Web log post]. Retrieved from http://the-f-word.org/blog/index.php/2007/11/01/pixar-joins-in-on-fat-bashing/

The-F-Word.org. (2008c, January 17). And another one bites the dust... [Web log post]. Retrieved from http://the-f-word.org/blog/index.php/2008/01/17/and-another-one-bites-the-dust/

The-F-Word.org. (2008b, March 15). Call for action: site for adolescent teens promotes eating disorders [Web log post]. Retrieved from http://the-f-word.org/blog/index.php/2008/03/15/callfor-action-site-for-adolescent-teens-promotes-eating-disorders/

The-F-Word.org. (2008a, January 19). Vern yip shows his true colors [Web log post]. Retrieved from http://the-f-word.org/blog/index.php/2008/01/19/vern-yip-shows-his-true-colors/

Thompson, C. J. (2004). Marketplace mythology and discourses of power. Journal of Consumer Research, 31(1), 162-180. doi: 10.1086/383432

Thompson, C. J., \& Coskuner-Balli, G. (2007). Countervailing market responses to corporate cooptation and the ideological recruitment of consumption communities. Journal of Consumer Research, 34(2), 135-152. doi: 10.1086/519143

Thompson, C. J., \& Haytko, D. L. (1997). Speaking of fashion: consumers' uses of fashion discourses and the appropriation of countervailing cultural meanings. Journal of Consumer Research, 24(1), 15-42. doi: 10.1086/209491

Vivelafat. (2008, March 17). Re: Quick hit: let P\&G know what you think of their website for girls [Web log comment]. Retrieved from http://kateharding.net/2008/03/17/quick-hit-let-pg-knowwhat-you-think-of-their-website-for-girls/

Wann, M. (2013, January 3). Big deal: you can be fat and fit. $C N N$, Opinion. Retrieved from http://edition.cnn.com/2013/01/03/opinion/wann-fat-and-fit-study/index.html

Ward, J. C., \& Ostrom, A. L. (2006). Complaining to the masses: the role of protest framing in customer-created complaint web sites. Journal of Consumer Research, 33(2), 220-230. doi: $10.1086 / 506303$

Young, J., \& Foot, K. (2005). Corporate e-cruiting: the construction of work in fortune 500 recruiting web sites. Journal of Computer-Mediated Communication, 11(1), 44-71. doi: 10.1111/j.10836101.2006.tb00303.x

YouTube. (2012). Women debate fat acceptance. CNN. Retrieved from http://www.youtube.com/watch?v=8qFIt7foyXs 


\section{APPENDIX}

\section{Blogs Sampled}

THE BLOG: The F-word

\section{URL}

Active period

Description

Comments policy http://the-f-word.org/blog/

$$
24^{\text {th }} \text { January } 2007-30^{\text {th }} \text { March } 2011
$$

"The F-word (Food, Fat and Feminism) is dedicated to talking about and sharing ideas about the intersections of these taboo and often weighty issues, while creating a dynamic and supportive community of food-loving, body-accepting feminists." (The-F-word.org, n.d.a)

"Opposing positions and/or contrasting opinions are very much welcomed here, but personal attacks and overarching assumptions and judgments towards others are not. The following kinds of comments will also never be approved on this blog:

1. Comments promoting weight-loss for the sake of weight-loss, commercial diets or other dieting behaviors. Not only are these kinds of comments potentially triggering for many readers here, they're also insanely boring.

2. No personal 'success' stories of how you lost weight, and we can too! Chances are I've lost more weight than you ever have in a shorter amount of time and I and many readers here are already well-informed on every weight-loss tactic under the sun.

3. 'Free speech' defenses. I am a journalist by trade, yes, but because this blog is my personal site and not a publicly-traded newspaper nor has it suddenly become the 51st state, I can make and enforce all the draconian measures I deem appropriate.

4. Uninformed and uneducated whines. I post citation information and links to studies I cite here whenever possible, but on the off-chance I don't, it's usually because I've posted it before. Instead of asking me to justify studies I cite, use the blog's search feature or Google and do your homework yourself.

5. Links to pro-ana/mia sites. My goal is for this site to be a pro-recovery site that also recognizes the realities those with eating disorders face on a daily basis. Still, links to sites which encourages disordered eating as a lifestyle or promotes dangerous behaviors isn't appropriate here. While I strongly welcome readers of pro-ana/mia sites to become involved in discussions here, I ask that they refrain from making any pro-ED comments or providing links to such sites.

Let's just play nice folks, and maybe we can all learn a thing or two." (The-F-word.org, n.d.b)

Advertising

N/A

The Bloggers

Rachel Richardson / Charlynn Schmiedt/ Greta Gleissner

Female(straight)/Female(straight)/Female(lesbian)

Gender 
Occupation

Location

The Posts: Average Posts/Week

Tags (from sidebars or posts)

\# of Subscribers (on Google Reader)

Links to other blogs in the sample?

\section{Positive reference to marketers (sample)}

The Biggest Loser/Jillian Michaels (indirect mention: is a big fan of Jillian Michaels' workout program)

RealKidz clothing ( praises plus sized clothing line for providing clothing that will "enhance girl's self-esteem by providing them with age appropriate clothing they look good in and are excited to wear)

Brigitte (German) magazine (announced it will use professional models in favour of "real women")

Glamour (praised or an "extraordinary dialogue on body image)

Journalist and food historian/ student/ grad student

USA/USA/USA

3.3

25 categories

975

Shapely Prose: yes

Feed Me: yes

Big Fat Blog: yes

Negative References to marketers (sample)

Advocate for a boycott of Ralph Lauren for firing an underweight supermodel claiming she was too fat

Nestle (for its skinny cow brand image depiction of women)

Tasty Bite (criticized for its comment on food products that says "too many calories make you fat" (Richardson, 2009)

Bacardi (criticized for their get an ugly girlfriend campaign)

Ralph Lauren again for a poorly photoshop image distorting the proportions of a woman's body.

THE BLOG: Big Fat Blog

\section{URL}

Active period

Description

Comments policy

Advertising

The Blogger

Gender

Occupation

\section{http://www.bigfatblog.com/}

August 18, 2000 - current (as of $21^{\text {st }}$ September 2012)

Big Fat Blog - BFB for short - was founded in August, 2000 and has its roots in size discrimination research I did in college. Since then BFB has been recognized as one of the grandpas of the fatosphere, helping in a small way to encourage others to blog about fat acceptance and fat rights. As of August 2008, the site has 2,700 registered members (though many are lurkers or inactive), and averages 65,000 unique visitors each month. Big Fat Blog still focuses on the media as it did in 2000 but has expanded to support the fatosphere with an events calendar, forums, activism, and lots more. In November, 2007, the first Big Fat Blog Think Tank was held in Chicago, Illinois, and helped launch the Coalition of Fat Rights Activists.

$\mathrm{n} / \mathrm{a}$

none

Paul Campos (creator) $\rightarrow$ A lot of the recent posts are written by Carrie Radian the President of the Fat Rights Coalition who took over the blog on April 1, 2009

male

Professor of Law

United States

Location

The Posts: Average Posts/Week 
Tags (from sidebars or posts)

\# of Subscribers (on Google Reader)

Links to other blogs in the sample?

\section{Positive reference to marketers (sample)}

Newsweek- Fat and Fit photo gallery, the Fat Wars series of articles

Drop Dead Diva (TV series) - mentions discrimination of fat people

Fat Fancy- "one of the most incredible fat clothing shops in the WORLD"

HAES

NAAFA- trying to change fat discrimination laws in Nevada

Politics, activism, fathletics, fat and health, discrimination, projects, the media, Call to Action, Acceptance, Fat and Women,

Quest for Thinness

928

Shapely Prose: yes

Feed Me: no

The F-word: yes

\section{Negative reference to marketers (sample)}

Lincoln University - controversial policy to make fatties take an extra class to learn how not to be fat

Weight Watchers- bad donation policy to help fight world hunger

Jon Stewart- unfair fat suit episode

North Caroline Fat Health plan - smokers with a lower BMI pay less for insurance coverage $\rightarrow$ discrimination

LighterLife- weight loss program resulted in at least three deaths

Drop Dead Diva- steoreotypes fat people as ones that don't take care of themselves

\section{THE BLOG: Feed Me}

URL

Active period

Description

Comments policy

Advertising

The Blogger

Gender

Occupation

Location

The Posts: Average Posts/Week

Tags (from sidebars or posts)

\# of Subscribers (on Google Reader)

Links to other blogs in the sample?

\section{Positive reference to marketers (sample)}

Dove: the building self esteem fund.

TV show "How to Look Good Naked" the premis of the show is that any women can look good naked if she loves her body.

Book review: Take charge of your child's eating disorder http://harrietbrown.blogspot.com/

June 25, $2006-3^{\text {rd }}$ July 2012

Talking about food, eating, body image, and weight

Comment moderation has been enabled. All comments must be approved by the blog author

Only an advertisement for Harriet's latest book

Harriet Brown

Female

Writer and Professor of Journalism

United States

39 categories, including HAES, healthy cooking, and dieting

568

Shapely Prose - yes

The F-word - yes

BFB -

\section{Negative reference to marketers (sample)}

United Airlines: flying whilst fat.

HappyHR: a wristband that calculates continuously the amount of calories you burn.

Proctor and Gamble sponsors a website and there is an unmoderated discussion for girls, and the comments get out of hand. 
Apple's Add campaign for the new iMac "You can't be too thin. Or too powerful.

PETA — sends an open letter to Micahel Moore urging him to go vegetarian. In it, it criticizes overweight individuals for causing decline in the health care system etc.

Slimfast spokeswomen, ex supermodel Rachel Hunter said in NeW York Magazine "Who doesn't want to lose 20 pounds?" (Harriet, 2007)

TLC show BIG Medicine: a show about a father-son doctor team that performs weight-loss surgery for people in an attempt to regain their lives.

THE BLOG: Shapely Prose

URL

Active period

Description

Comments policy http://kateharding.net/

January 2007- September 2010

A blog dedicated to fat-acceptance, feminism, politics, and other topics.

A long comments policy (14 rules). Read full version at: http://kateharding.net/comments-policy/

I don't know how to make this any clearer than I already have: Commenting here is not a right, and decisions about what's appropriate are not made democratically. Each of the five bloggers here has complete authority to moderate as she sees fit. It is straight-up dictatorial, and not always benevolent. Some of us are more naturally inclined to couch warnings with assurances that we get what you're trying to say and know you're not a bad person or whatever. But none of us do that every time, and every official statement about our policies has reinforced the basic point that we feel no obligation to be patient, issue warm fuzzies, poll commenters on whether we're overreacting or hold back when we're pissed off. Moderating is a lot of work for zero remuneration, especially now that every post gets hundreds of responses, and sometimes, we do not have the energy to say anything beyond, "You are getting on my tits, and it needs to stop. Now." (Harding, 2010)

Advertising

The Blogger(s)

None, except for the bloggers' books.

Kate Harding; A Sarah (May 2009-February 2010); Fillyjonk (August 2007-April 2010); Snarky's Machine (November 2009-May 2010); Sweet Machine (August 2007-April 2010)

Gender

Female (all)

Respectively: writer and editor, professor of religion, N/A, performer and storyteller, graduate student.

United States 7

52 categories, including Media, Exercise, Politics, Selfimage, Food, Reading, Medicine, Fluff.

3.062 
Links to other blogs in the sample?

Positive reference to marketers (sample)

Boutique Lucie Lu and their clothing options

V Magazine's plus size fashion shoot

Etsy online marketplace

Igigi store
Feed $\mathrm{Me}-$ yes

The F-word - yes

BFB - yes

Negative reference to marketers (sample)

PETA advertisements

American Apparel advertisements

Weight Watchers claims

Plus size clothing line of Forever 21

Southwestern airlines for demanding fat passengers to purchase two seats. 